\title{
Weekly cycles in meteorological variables over large-scales: fact or myth?
}

Arturo Sanchez-Lorenzo ${ }^{1}$, Patrick Laux ${ }^{2}$, Harrie-Jan Hendricks-Franssen ${ }^{3}$, Aristeidis K. Georgoulias ${ }^{4}$, Josep Calbó5 ${ }^{5}$, Stefanie Vogl2 ${ }^{2}$, Johannes Quaas ${ }^{6}$

${ }^{1}$ Institute for Atmospheric and Climate Science, ETH Zürich, Zürich, Switzerland

${ }^{2}$ Karlsruhe Institute of Technology (KIT), Institute for Meteorology and Climate Research (IMK-IFU), Garmisch-Partenkirche, Germany

${ }^{3}$ Forschungszentrum Jülich GmbH, Agrosphere Institute (IBG-3), Jülich, Germany

${ }^{4}$ Laboratory of Atmospheric Pollution and Pollution Control Engineering of Atmospheric Pollutants, Department of Environmental Engineering, Democritus University of Thrace, Xanthi, Greece

${ }^{5}$ University of Girona, Department of Physics, Girona, Spain

${ }^{6}$ University of Leipzig, Institute for Meteorology, Leipzig, Germany

\section{MONTUE WED THU FRI SAT SUN}

arturo.sanchez@env.ethz.ch argeor@env.duth.gr 
Weekly cycles in meteorological variables over large-scales: fact or myth?

$1^{\text {th }}$ International Conference on Meteorology, Climatology and Atmospheric Physics - COMECAP 2012, Athens, 29 May - 1 J une

\section{Weekly cycles: A brief review}

"Except the lunar phases with a period of 7.38 days, negligible in terms of the day of the week for 44 years, there is no other known natural periodicity that can generate a weekly cycle. Thus, it is plausible to relate the detected weekly periodicities with the human activity cycle and consequently it is possible to argue that the anthropogenic disturbances (such as pollutant emissions) may interact with local or larger scales affecting the atmospheric dynamics."

(Sanchez-Lorenzo et al., 2008) 
Weekly cycles in meteorological variables over large-scales: fact or myth? $11^{\text {th }}$ International Conference on Meteorology, Climatology and Atmospheric Physics - COMECAP 2012, Athens, 29 May - 1 J une

\section{Day of the week variability: An old idea}

Ashworth (1929) first observed Sunday rainfall minima for a polluted city in England (Rochdale)
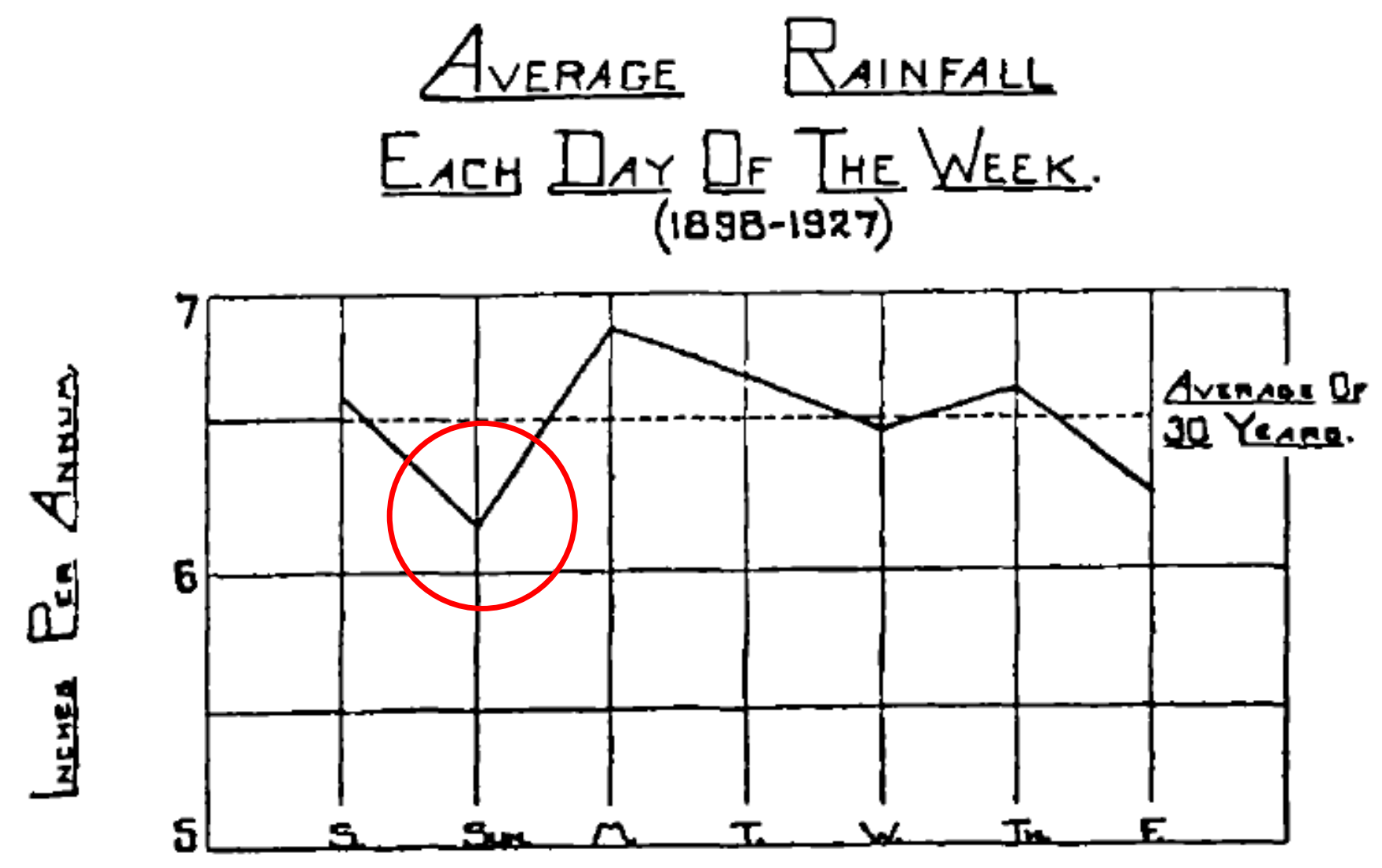
(a)

e


$1^{\text {th }}$ International Conference on Meteorology, Climatology and Atmospheric Physics - COMECAP 2012, Athens, 29 May - 1 J une

\section{Large-scale weekly cycles of meteorological variables}

1. Gordon (1994) analyzed lower troposphere temperatures from NOAA satellites (differences between Wednesday and Sunday in the Northern Hemisphere

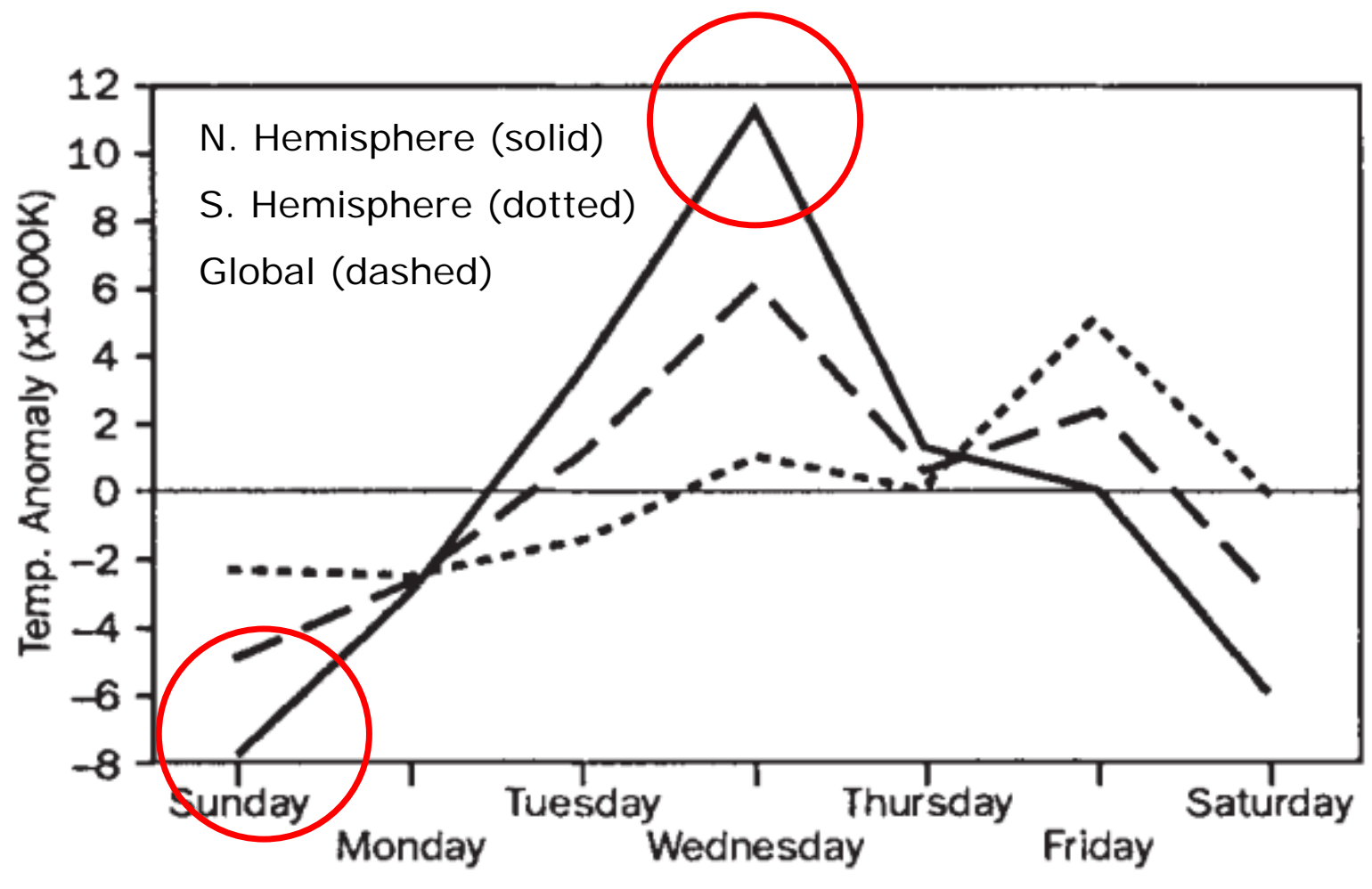


$11^{\text {th }}$ International Conference on Meteorology, Climatology and Atmospheric Physics - COMECAP 2012, Athens, 29 May - 1 J une

\section{Large-scale weekly cycles of meteorological variables}

2. Cerveny and Balling (1998) used satellite-derived precipitation estimates from MSU aboard TIROS-N satellites over the East coast of the United States (midweek-weekend differences)
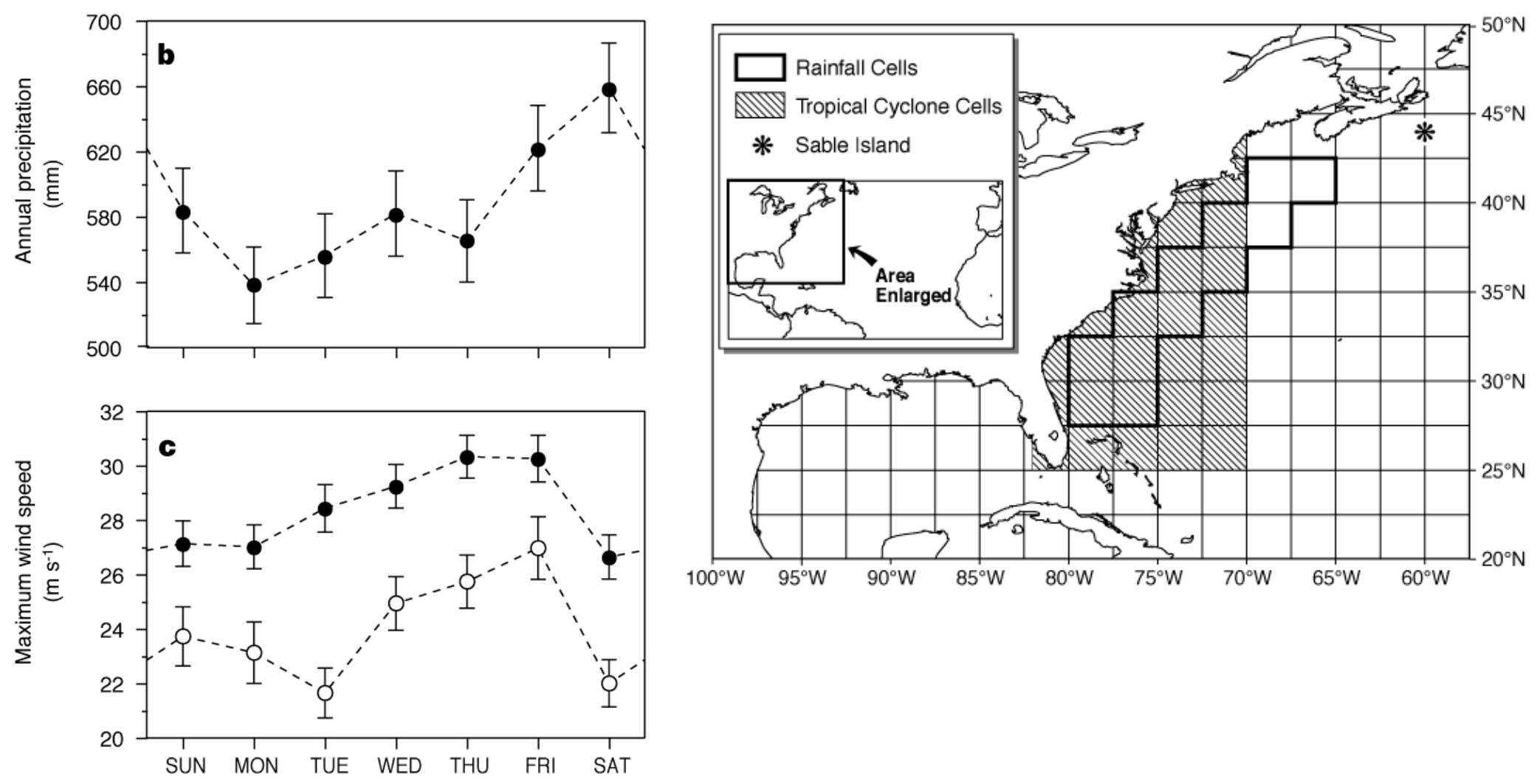
$1^{\text {th }}$ International Conference on Meteorology, Climatology and Atmospheric Physics - COMECAP 2012, Athens, 29 May - 1 June

\section{Large-scale weekly cycles of meteorological variables}

3. Forster and Solomon (2003) examined the "weekend effect" in diurnal temperature range (DTR) for many stations worldwide
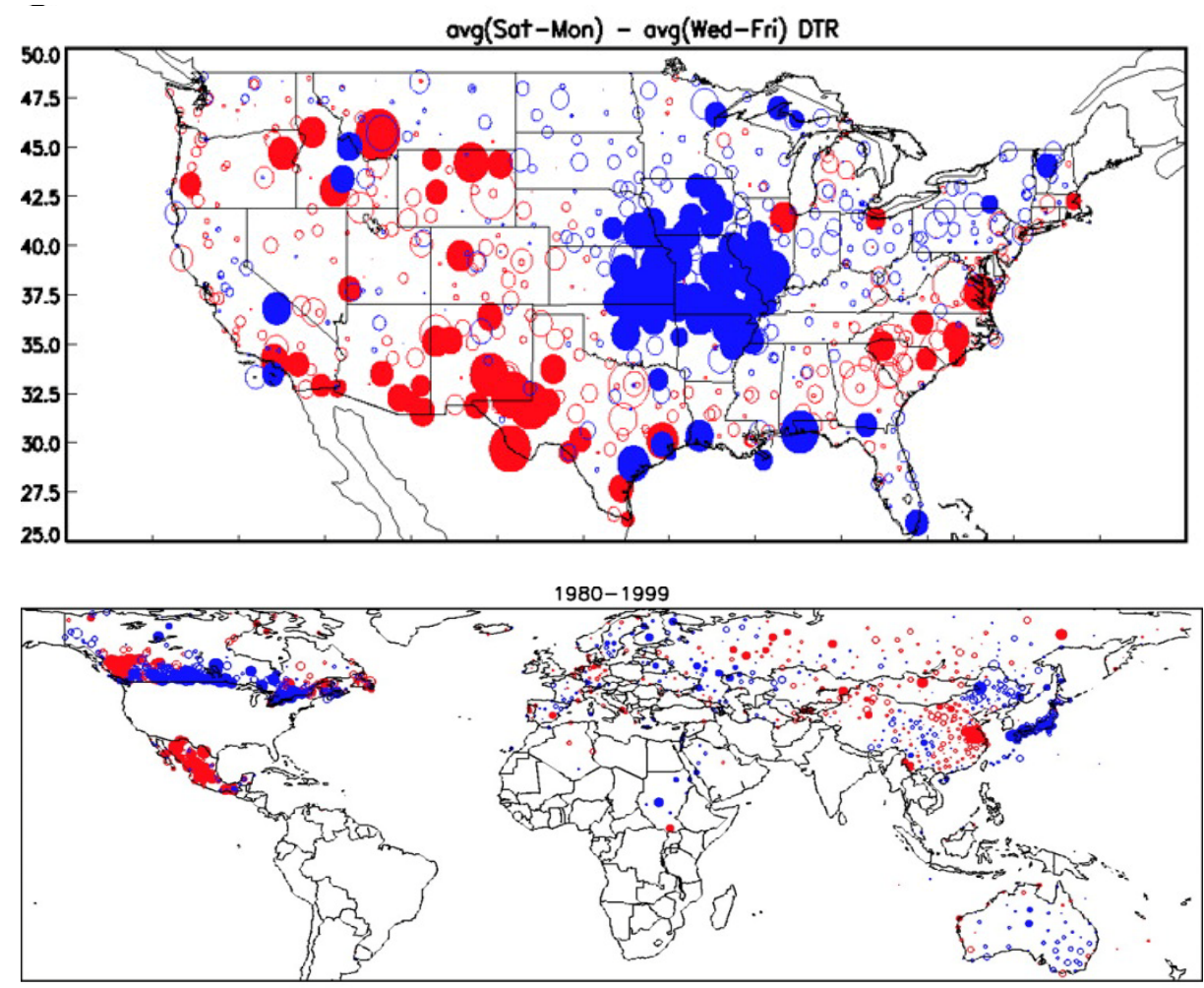

DTR difference $(K)$

$\begin{array}{cccccccc}0.05 & 0.10 & 0.15 & 0.20 & 0.25 & 0.30 & 0.35 & 0.40\end{array}$


$11^{\text {th }}$ International Conference on Meteorology, Climatology and Atmospheric Physics - COMECAP 2012, Athens, 29 May - 1 J une

\section{Large-scale weekly cycles of meteorological variables}

4. Bell et al. (2008) studied the weekly cycle of rainfall over southeast U.S. in summer. Rainfall over $B(C)$ area is higher (lower) during the weekdays (weekends). Explained through a midweek suppression of afternoon storms over $\mathrm{C}$ due to convection invigoration over $\mathrm{B}$

Averaging Regions

30

20
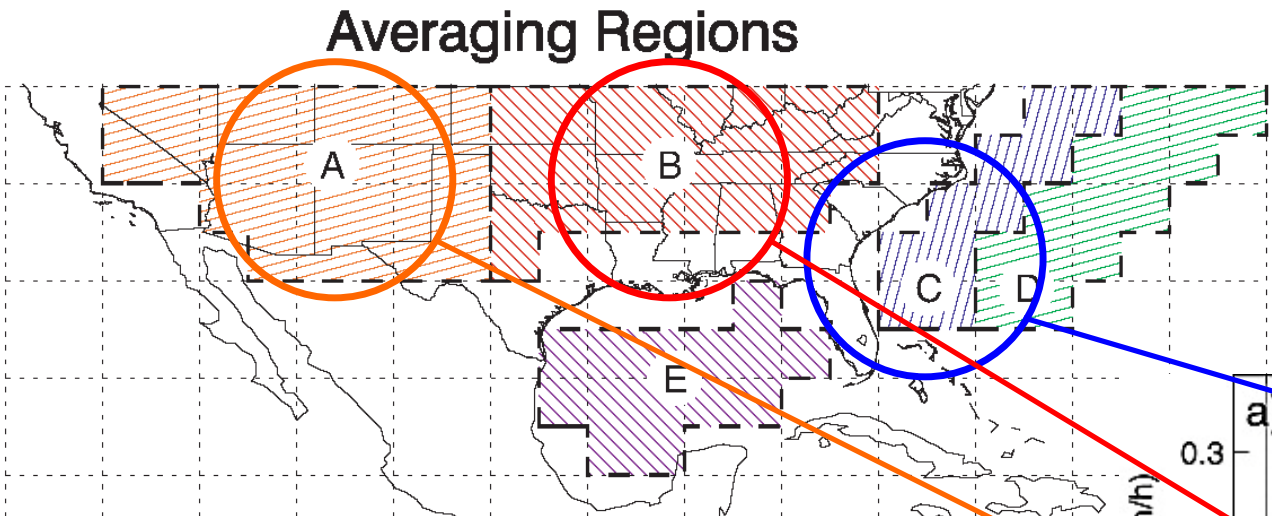
$-80$

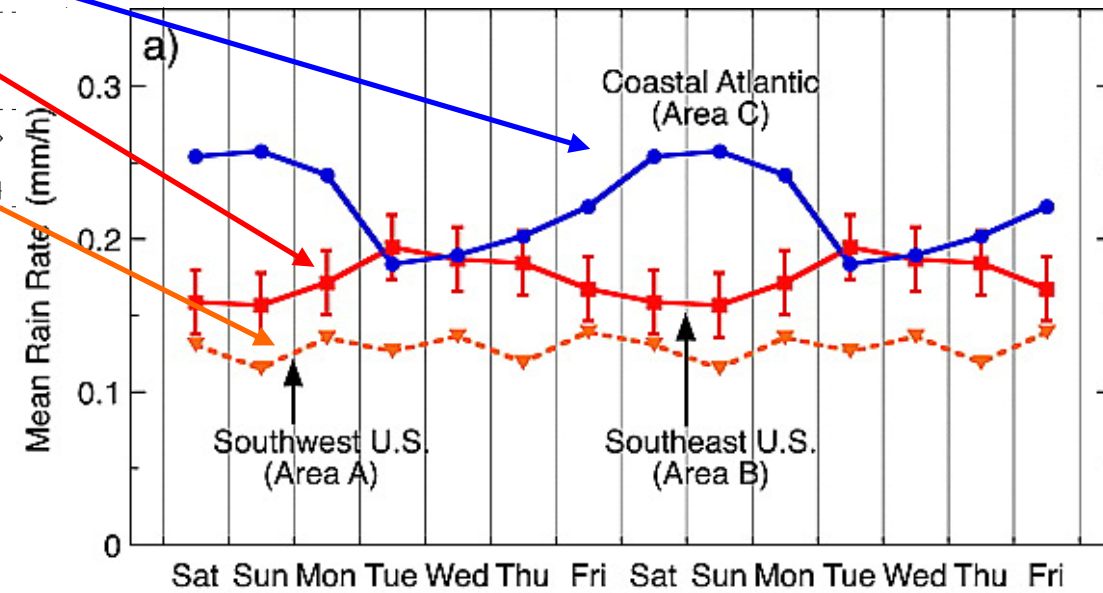


Weekly cycles in meteorological variables over large-scales: fact or myth?

$1^{\text {th }}$ International Conference on Meteorology, Climatology and Atmospheric Physics - COMECAP 2012, Athens, 29 May - 1 J une

\section{Large-scale weekly cycles of meteorological variables}

5. Among others, Gong et al. (2007) reported significant weekly cycles in different meteorological variables over China; e.g. wind speed at surface is lower (higher) in the early (latter) part of the week. Opposite cycle is observed in temperature
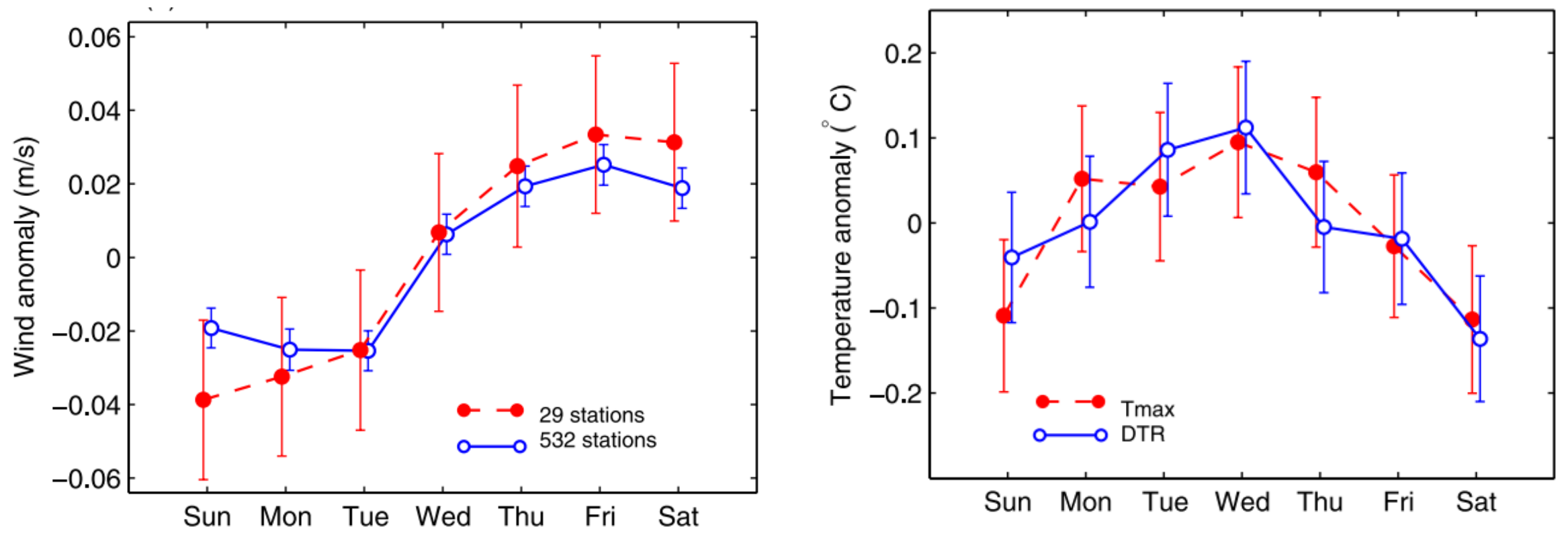
Weekly cycles in meteorological variables over large-scales: fact or myth?

$11^{\text {th }}$ International Conference on Meteorology, Climatology and Atmospheric Physics - COMECAP 2012, Athens, 29 May - 1 J une

\section{Large-scale weekly cycles: uncertainties}

- Few studies over Europe with controversies regarding the stat. significance of the results (e.g. Bäumer and Vogel, 2007; Hendricks Franssen, 2008; Laux and Kunstmann, 2008; Sanchez-Lorenzo et al., 2008, 2009; Hendricks Franssen et al., 2009; Quass et al., 2009)

- The existence of a significant precipitation weekly cycle in the U.S. has also been challenged (DeLisi et al., 2001; Schultz et al., 2007 and references therein)

- Overall, there are some general shortcomings in the methods used to assess the significance of the weekly cycles; e.g. to neglect the spatial autocorrelation of the data, the assumption of normality in the time series

For more details see: Sanchez-Lorenzo, A., Laux, P., Hendricks-Franssen, H.-J., Calbó, J., Vogl, S., Georgoulias, A. K., and Quaas, J.: Assessing large-scale weekly cycles in meteorological variables: a review, Atmos. Chem. Phys. Discuss., 12, 1451-1491, doi:10.5194/acpd-12-1451-2012, 2012. 